\title{
O PROCESSO INDUSTRIAL E SUA EXPANSÃO ECONÔMICA NA CIDADE DE FEIRA DE SANTANA/BAHIA, BRASIL
}

\author{
Gracielle Mascarenhas Leite $^{\mathbf{1}}$; Suzi de Almeida Vasconcelos Barboni ${ }^{\mathbf{2}}$; \\ 1. Bolsista PIBIC/FAPESB, Graduanda em Ciências Econômicas, Universidade Estadual de Feira de Santana, e-mail: \\ graciellemascarenhas@gmail.com \\ 2. Orientadora, Departamento de Ciências Biológicas, Universidade Estadual de Feira de Santana, e-mail: \\ suziavbarboni@gmail.com
}

PALAVRAS-CHAVE: Feira de Santana; Indústria; Economia.

\section{INTRODUÇÃO}

Esta pesquisa tem como objetivo principal analisar o processo de transformação urbana, industrial e econômica da cidade de Feira de Santana - Bahia, no período de 1999 até 2016, visando observar, principalmente, as consequências geradas a partir da implantação do Centro Industrial do Subaé (CIS) e destacando sua devida importância, que decorre de uma política fundamentada de forma intencionada, com intuito de trazer desenvolvimento local e regional nos setores econômicos e sociais.

Este trabalho, em um primeiro momento, introduz o processo de industrialização na Bahia de forma ampla, em seguida, contextualiza a relação da cidade feirense com o CIS e depois, discorre sobre a literatura histórica nacional para melhor entendimento do mencionado tema. Posteriormente, busca esclarecer o processo industrial em Feira de Santana, falando da implantação do CIS e, finalmente, apresenta as transformações e os resultados decorrentes de todo o estudo, levando em consideração desde a população até a participação economicamente no PIB regional e nacional. Especificamente, procurar averiguar: i) fatores decorrentes da instalação do CIS em Feira de Santana; ii) o motivo do movimento de entrada e saída de habitantes da cidade; iii) nível de instrução dos empregados; iv) número e perfil das industrias atuais ativas; v) número das importações e exportações; vi) PIB municipal; vii) PIB per capita; viii) PIB das indústrias; e ix) participação nas atividades econômicas.

\section{MATERIAL E MÉTODOS OU METODOLOGIA (ou equivalente)}

A metodologia foi realizada a partir do levantamento de informações bibliográficas e dados disponibilizados pela Secretaria Municipal de Planejamento de Feira de Santana, Universidade Estadual de Feira de Santana (Coordenação de Pesquisa e Extensão do Departamento de Ciências Humanas e Filosofia e Biblioteca), Museu Casa do Sertão, Arquivo Público Municipal, e pelos sites do Instituto Brasileiro de Geografia e Estatística, Instituto de Pesquisa Econômica Aplicada, Centro Industrial do Subaé, Câmara de Dirigentes Lojistas de Feira de Santana, Superintendência de Estudos Econômicos e Sociais da Bahia, Deepask, além de artigos da internet (Google Acadêmico). A ferramenta utilizada na construção de gráficos foi o Microsoft Excel o qual pode proporcionar interpretações e conclusões claras dos dados econômicos e sociais estudados durante os anos de 1999 até 2016.

\section{RESULTADOS E/OU DISCUSSÃO (ou Análise e discussão dos resultados)}

O estudo desenvolvido sobre o tema satisfez os objetivos propostos e esperados, pois com a implantação do CIS na cidade pode-se vivenciar um processo significativo chamado urbanização e que esta trouxe consigo características desenvolvimentistas aderentes do fenômeno. 
A industrialização em Feira de Santana parece ter se desenvolvido "voltada para fora", numa "economia dependente de capital externo", condicionada pelos "contextos internacionais de maior ou menor liquidez". A partir deste reconhecimento elaboramos três proposições, baseado em Lamonica (2011):

1. os dados mostram uma relação positiva entre o crescimento da indústria em Feira de Santana e o aumento da taxa de urbanização;

2. há uma relação positiva entre a taxa de crescimento urbano e a infraestrutura da cidade, sendo a relação de causalidade na direção de aumento da atividade comercial, ampliação da malha rodoviária e comércio exterior;

3. observou-se que quanto maior a taxa de crescimento do comércio e das exportações, maior o crescimento do PIB.

Visto que o CIS ainda se elege como um dos principais objetos influentes no desenvolvimento local/regional durante os anos de 1999 até 2016, os dados abaixo comprovaram as informações acima:

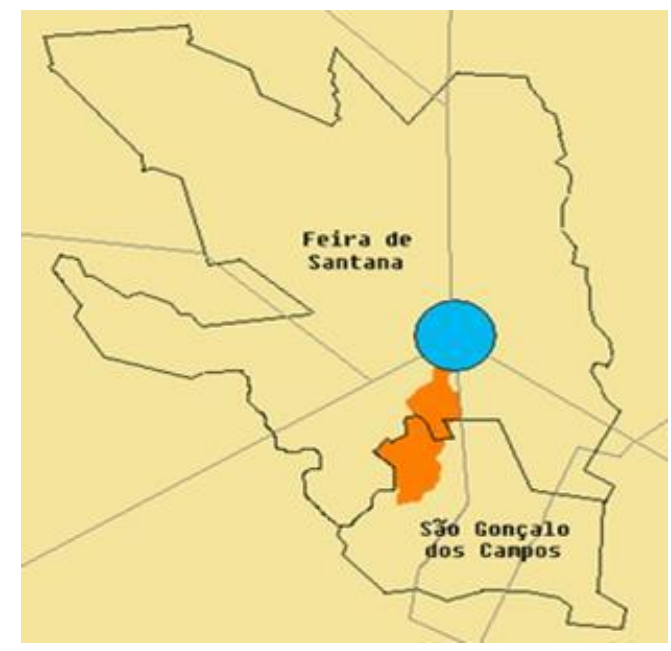

Figura 1: Mapa correspondente à aérea do Centro Industrial em Feira de Santana/Bahia.
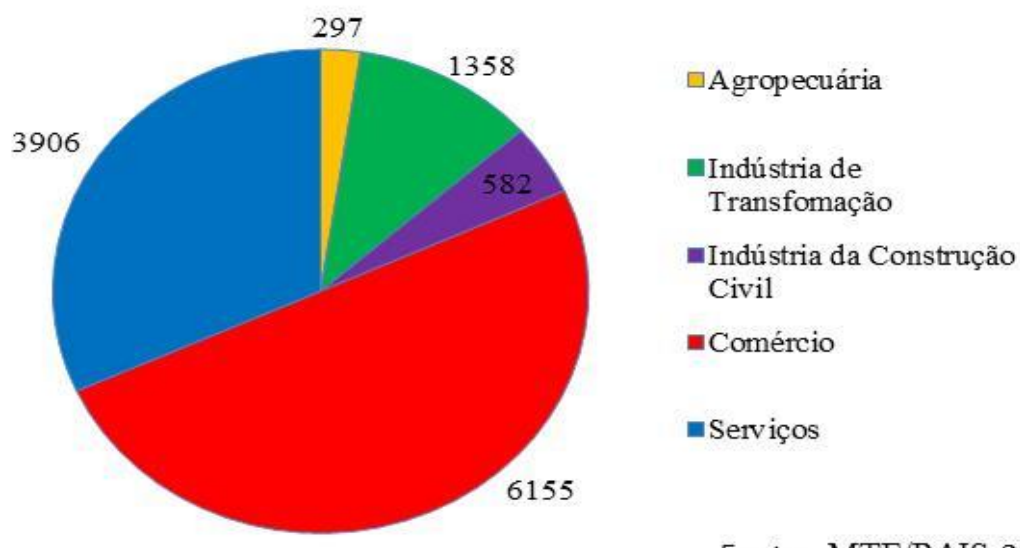

Fonte: MTE/RAIS 2014

Figura 2: Estabelecimentos do mercado formal por atividade econômica na cidade de Feira de Santana/Bahia no período de 2014. 


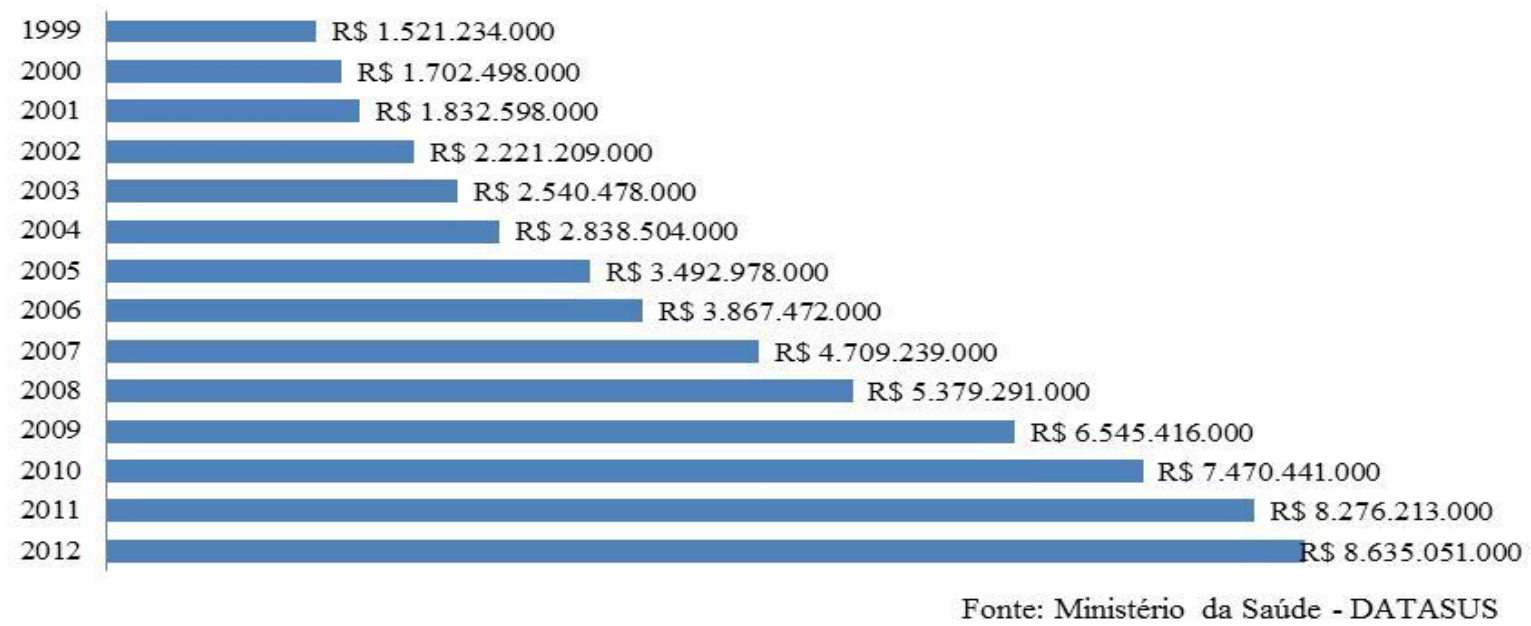

Figura 3: PIB da cidade de Feira de Santana/Bahia no período de 1999 até 2012.

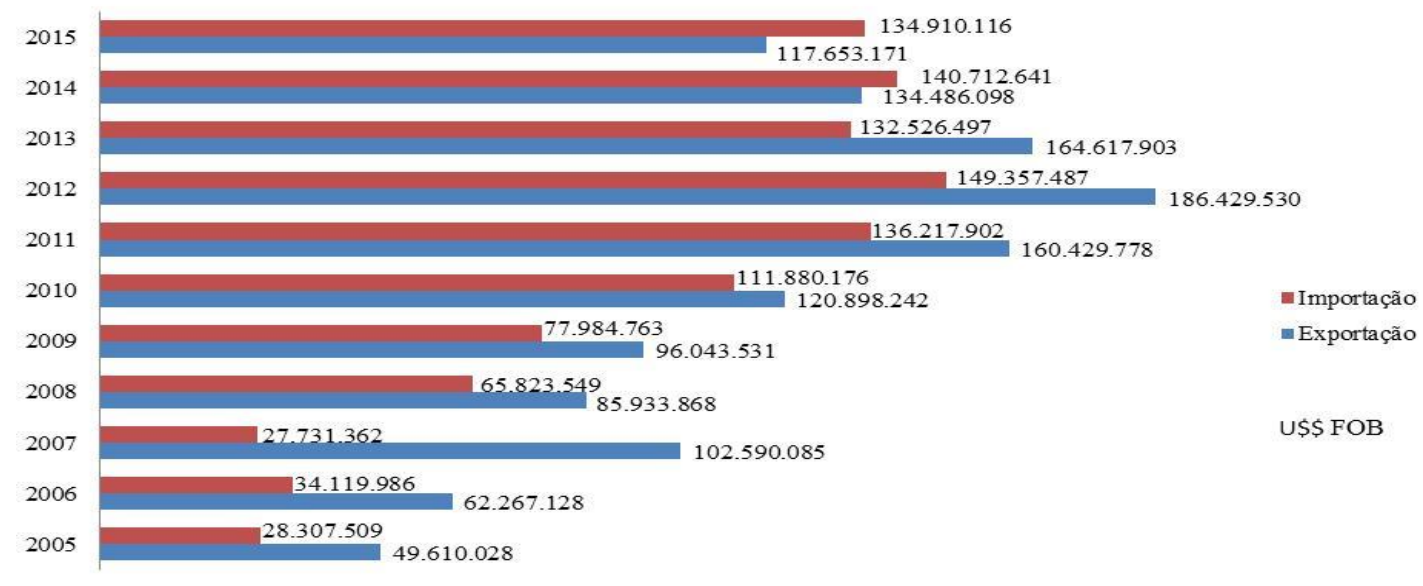

Fonte: Ministério do Desenvolvimento Indústria e Comércio Exterior

Figura 4: Feira de Santana/Bahia: Importação x Exportação no período de 2005 até 2015.

\section{CONSIDERAÇÕES FINAIS (ou Conclusão)}

Com o estudo histórico e estrutural sobre a modernização industrial feirense, pode-se afirmar que, a implantação do CIS na cidade foi crucial no desenvolvimento local/regional que se tem atualmente e trouxe resultados importantes para o desenvolvimento econômico da cidade. É considerável a importância que o governo teve em intervir nessa política de modo a configurar a desconcentração industrial no país e proporcionar facilidades de investimentos às empresas estrangeiras e nacionais na urbe feirense.

A partir dos resultados obtidos foi possível verificar que para se garantir uma economia desenvolvida é necessário um processo de industrialização, e que o mesmo, depende de um cenário macroeconômico positivo contribuindo com o desenvolvimento. $\mathrm{O}$ crescimento econômico, em si, deriva de uma dinâmica da demanda agregada, que através da economia de mercado aberto, possibilita estratégias competitivas no setor de exportações. Constata-se que na década de 1970 , o crescimento acelerado da economia brasileira teve sua fase final e que foi marcado pelo momento de substituição de importações.

Contribuiu também para o grande número de empregos direitos e indiretos na região, aumento da população e melhoria da infraestrutura. 
Com $3^{\mathrm{a}}$ posição no ranking de PIB estadual, é um dos principais municípios que mais importam e exportam bens e serviços produzidos, trazendo desenvolvimento para a economia feirense e baiana.

Outras consequências do desenvolvimento feirense vêm em torno da desigualdade social, considerada a $27^{\mathrm{a}}$ cidade mais violenta do mundo.

\section{REFERÊNCIAS}

ALMEIDA, Janeide Oliveira da Silva. A implantação do Centro Industrial do Subaé em Feira de Santana - Bahia através de uma industrialização planejada. Feira de Santana, BA: UEFS.

Anuário Estatístico de Feira de Santana. Feira de Santana, BA: CDL, 2012.

ARAÚJO, Alexandra Oliveira. O comércio informal em Feira de Santana - Bahia - Brasil: permanências e mudanças. Feira de Santana, BA: UEFS.

CDL Feira de Santana - Publicações. Disponível em: $<\underline{\text { http: } / / \text { www.cdlfs.com.br/index.php?option=com content } \& \text { view }=\text { article } \& \text { id }=83 \& \text { Itemid }=222}$ \#aspectos_eco>. Acesso em 11 abril/2016.

Centro Industrial do Subaé - Indústrias. Disponível em: <http://www.cis.ba.gov.br/modules/conteudo/conteudo.php?conteudo=8 >. Acesso em 11 abril/2016.

CRUZ, Rossine Cerqueira. A inserção de Feira de Santana (BA) nos processos de integração produtiva e de desconcentração econômica nacional. Campinas, SP: UNICAMP, 1999.

Deespask: o mundo e as cidades através de gráficos e mapas - Pib indústria. Disponivel em: <http://www.deepask.com/goes?page=PIB-Industria_324_109>. Acesso em 11 abril/2016.

FREITAS, Nacelice Barbosa. Mordenização industrial em Feira de Santana: uma análise a da implantação do Centro Industrial do Subaé - CIS. Feira de Santana, BA: Sitientibus: UEFS, 2009.

FREITAS, Nacelice Barbosa. Urbanização em Feira de Santana: influência da industrialização 1970-1996. Salvador, BA: UFBA, 1998.

IBGE - Instituto Brasileiro de Geografia e Estatística - Cidades. Disponível em: <http://cidades.ibge.gov.br/painel/painel.php?codmun=291080 >. Acesso em $11 \mathrm{abril} / 2016$.

Informações do Brasil - Informações sobre cidades. Disponível em: <http://informacoesdobrasil.com.br/pesquisa.html $>$. Acesso em 11 abril/2016.

LAMONICA, Marcos Tostes; FEIJO, Carmen Aparecida de. Crescimento e industrialização no Brasil: uma interpretação à luz das propostas de Kaldor. Rev. Econ. Polit., São Paulo, v. 31, n. 1, p. 118-138, Disponível em: <http://www.scielo.br/pdf/rep/v31n1/a06v31n1.pdf.>. Acesso em 11 abril/2016.

OLIVEIRA, Maria Leny Souza. Feira de Santana no contexto da urbanização brasileira e a questão da moradia na favela. Feira de Santana, BA: UEFS Editora, 2014.

SANTOS, Lucas Bispo de Oliveira e Henrique, Wendel. Caracterização da evolução urbana e da situação urbana atual de Feira de Santana. Salvador, BA: UFBA.

SILVA, Alex de Souza. A influência do Centro Industrial do Subaé (CIS) no processo de urbanização do bairro do Tomba: um estudo de caso no município de Feira de Santana-Ba. Salvador, BA: UNIFACS, 2010.

SUZIAN, Wilson. Indústria Brasileira: origem e desenvolvimento. São Paulo: Hucitec, 2000.

SUZIGAN, Wilson. Industrialização na visão de Celso Furtado. Instituto de economia: UNICAMP.

TEIXEIRA, Francisco e GUERRA, Oswaldo. 50 Anos da Industrialização Baiana: do enigma a uma dinâmica exógena e espasmódica. Salvador, BA: Bahia Análise e Dados - SEI: Julho 2000 . 